\title{
Dwelling in Marble Halls: \\ A Relevance-Theoretic Approach to Intertextuality in Translation
}

\author{
Eva M. Almazán García \\ University of Vigo \\ eag@uvigo.es
}

\begin{abstract}
In this article we explore the possibility of using a relevance-theoretic approach for translating intertextual references in a literary context. On the basis of an example taken from L.M. Montgomery's Anne of Green Gables, we propose an interpretation of the original text based on concepts taken from Relevance Theory (henceforth RT) as designed by Sperber and Wilson (1986) and developed by Blakemore (1992). Gutt's contribution (1991), viewed as an insightful but still preliminary step towards an application of RT to the theory and practice of translation, is then made to crystalize in valid criteria which may orient the translator in the decision-making process.
\end{abstract}

\section{Introduction}

In this paper we intend to show how RT as originally framed by Sperber and Wilson (1986) and applied to translation by Gutt (1991) can prove a useful integrative tool when it comes to dealing with intertextuality in translation. This specific application is twofold. In the first place, it will serve as an instrument of interpretation of the original text. Secondly, as a criterion for translation viewed as a decision-making activity.

We do not purport to offer a universal set of rules for tackling intertextual reference -quite on the contrary, our intention is to rely heavily on the real-life example that inspired this practical application of some ideas of RT. Nevertheless, by showing how those ideas 
render aid in a particular translation situation we want to suggest that a more ambitious development is not out of the question.

\section{Intertextuality}

In an article significantly entitled "Intertextualities" (our emphasis), Plett (1991: 3-29) presents a synthetic view of the different positions in the current debate on intertextuality. On the basis of what he calls attitudes towards intertextuality he distinguishes between progressive intertextualists and traditionalist intertextualists, both groups being confronted by "a phalanx of anti-intertextualists" (Plett, 1991: 3) whose views are not relevant for the present discussion.

For progressive intertextualists, intertextuality determines the text's ontological status: all texts are intertextual by definition. Julia Kristeva's reflections on Mikhail Bakhtin's work are usually referred to as the origin of this notion: "any text is constructed as a mosaic of quotations; any text is the absorption and transformation of another" (Kristeva, 1986: 37). The subsequent elaboration of this idea by Kristevian circles and the apostles of Poststructuralism and Deconstructionism, Barthes and Derrida, has inspired a highly sophisticated but definitely abstract discourse which cannot - and is not intended to- be practically applied. In Plett's words: "This 'school' has never developed a comprehensible and teachable method of textual analysis" (Plett, 1991:4).

Traditionalist intertextualists are, according to Plett, those orthodox literary scholars who attempted to reconcile what they had been doing for years -identifying and explaining allusions made in a literary work to another work - with the modern, fashionable concept of intertextuality, with a view to updating and salvaging an all too often demeaned activity. The symbiotic attempt was successful "at least partly, in making the approach more applicable" (Plett, 1991: 4) and in superseding the old positivistic ways: "Allusional studies no longer focus on an allusion's implicitness or explicitness, but direct attention to its relational quality" (Hebel, 1991:136).

We would like to draw attention to the existence of a third academic attitude towards intertextuality: a linguistically oriented approach -as opposed to the philosophically and philologically oriented approaches discusses by Plett.

Beaugrande and Dressler (1981) called intertextuality "the seventh standard of textuality" (Beaugrande and Dressler, 1981:10), thus making explicit the link between this concept and Text Linguistics. An approach paradigmatically based on communication, Text Linguistics functions as the bridge through which the debate on intertextuality moves on to Cognitive Linguistics and acquires a distinct up-to-date status. Intertextuality is now studied in terms of the mental processes by which intertextual references are produced and interpreted.

Note that the two paradigms we have just mentioned as constituents of the linguistically oriented attitude towards intertextuality are communication and cognition: it is not a coincidence that this phrase is the subtitle of Sperber and Wilson's celebrated book. 
Although we do not intend to elaborate a complete relevance-based theory of intertextuality, we will try to adopt this approach and combine relevance and intertextuality in our search for instruments which may help translators deal with intertextual references.

\section{A relevance-theoretic approach to translation}

Sperber and Wilson's RT is presented as a cognition-based account of human communication. That translators are communicators is an intuition that seems to be universally accepted. Assuming that Sperber and Wilson's RT successfully accounts for human communication and that translators are communicators, as universally accepted, it follows that the principles which according to RT govern linguistic communication in general also govern translation in particular.

This is Gutt's main thesis in Translation and Relevance (1991). In his study he addresses translation in relevance-theoretic terms and tries to explain some translation decisions with the help of relevance-theoretic tools. He also shows how translators do think intuitively in terms of cognitive cost and benefit. He advances the hypothesis that the whole edifice of translation theory has contributed to hide and obscure such valid effort-reward intuitions and raises the claim that the phenomenon known as translation can and must be explained as an instance of communication as viewed by RT - solutions to particular translation problems will naturally stem, he argues, from such an explanation, there being no need to elaborate standard translation recipes.

One of the main problems of Gutt's contribution to the present-day reflection on translation has been shown to be the lack of tangible results: as a theory it has been said to be "not very illuminating" (Tirkkonen-Condit, 1992: 243), whereas as a practical method it has often been dismissed as either too vague and consequently useless or even nonexistent, since Gutt's discussion of examples usually takes the form of an explanation, a justification or a critique of translation decisions already made.

Our present approach attempts at exploring the extent to which the problem of such an apparent lack of practical utility can be solved by making, not just explaining, translation decisions in the light of RT. This implies putting to the test Gutt's proposal that decisionmaking recipes involving concepts such as faithfulness, equivalence, authorial intention, etc. should be abandoned in our search for more intuitive, but theoretically justified, notions. It also calls for an interpretation of the original text made in the light of RT. Some attempts in this line have already been made: see for example Dahlgren (1998) on poetry and translation.

Our insisting on the need of making particular and distinct what is general and vague should suffice as evidence that we have no interest in offering universal models of action. Our goal is a) to produce an appropriate translation of the example discussed - an instance of intertextuality, traditionally considered a translation problem (see for example Leppihalme, 1997) - and b) to do so on safer theoretical grounds allowing a justification other than personal taste (Kussmaul, 1995: 3). 


\section{Interpreting the original text}

As stated above, the present discussion relies heavily on a real instance of intertextuality with which the translator is confronted in a real translation situation. The intertextual reference in question is taken from L. M. Montgomery's Anne of Green Gables (1997), furst published in 1908. Matthew Cuthbert and his sister Marilla are adopting an orphan boy to help them run their Prince Edward Island farm. Matthew drives to the station, where he is supposed to fetch the orphan boy. When he gets there, he is most surprised to see that the child sent by the asylum is a girl instead of the expected boy. That orphan girl, Anne Shirley, will be the main character of the story. In this particular excerpt, taken from the second chapter, both Matthew and the reader get their very first impression of her.

I suppose you are Mr Matthew Cuthbert of Green Gables?" she said in a peculiarly clear, sweet voice. "I'm very glad to see you. I was beginning to be afraid you weren't coming for me and I was imagining all the things that might have happened to prevent you. I had made up my mind that if you didn't come for me tonight I'd go down the track to that big wild cherry-tree at the bend, and climb up into it to stay all night. I wouldn't be a bit afraid, and it would be lovely to sleep in a wild cherry-tree all white with bloom in the moonshine, don't you think? You could imagine you were dwelling in marble halls couldn't you? And I was quite sure you would come for me in the morning, if you didn't tonight (1997: 52).

When Anne says to Matthew "You could imagine you were dwelling in marble halls, couldn't you?" she is making an intertextual reference to "I Dreamt that I Dwelt in Marble Halls", a popular ballad from Michael William Balfe's operetta The Bohemian Girl (1843). Its plot can be summarised as follows: Arline, a gypsy girl who leads a nomadic life, has a strange dream - she is the daughter of a noble family, respected and rich, surrounded by admirers and servants, and lives in a sumptuous castle. The dream, which Arline discards as a figment of her imagination, is in fact a real memory of her childhood, since she is actually the lost daughter of a count. In the end, the Bohemian girl is recognised by her father and returns to the aristocratic environment that she had evoked in her dream.

The hypothesis that the reader of the original text at the time of publication would immediately spot this intertextual reference and draw some conclusions from it is highly plausible, and so is the hypothesis that the author was perfectly conscious of it and used it as a strategy to transmit a particular impression of Anne. Barry, Doody and Doody Jones (1997) point out that the author added this and several other remarks to Anne's speech in a revision of her first draft. According to their analysis, "the voice of Anne is not yet fully developed in the very first writing" (1997: 21) and this intertextual reference, as well as some others, was inserted studiously at a later stage so that it has a bearing on the first impression that the reader has of Anne.

Let us assume that both hypotheses are correct and try to reconstruct in relevancetheoretic terms both the effect which this intertextual reference had on the original reader and the possible intentions underlying Maud Montgomery's decision. Such a reconstruction will rest on two key notions taken from RT: poetic use and interpretive use. 
It would be defensible to list intertextuality next to metaphor under the heading "poetic effects', since intertextual references often achieve most of their relevance through the effect of what Blakemore calls "a wide array of weak implicatures" (1992: 157). Anne's reference to "I Dreamt that I Dwelt in Marble Halls" seems to confirm this intuition in that it functions, as it will be shown, as an instance of weak communication.

Nevertheless, it also gives rise to a layer of implicatures which must be labelled as strong. Therefore, rather than producing a universal characterisation of intertextuality as having a poetic effect, we suggest that an interesting analysis of this particular intertextual reference involves paying attention to the whole continuum of implicatures.

Hence, on the basis of the notions of strong and weak communication three rough sets of premises used, and contextual implications derived, by the reader can be identified:

(a) There exists a layer of strong implicatures, indispensable for the reader to find an interpretation consistent with the second -or communicative- principle of relevance (Sperber and Wilson, 1995: 260-261; hereafter principle of relevance).

(...) it would be lovely to sleep in a wild cherry-tree all white with bloom in the moonshine, don't you think? You could imagine you were dwelling in marble halls, couldn't you?

The presumption of relevance entitles the reader to automatically take for granted that Anne is at least trying to be relevant, which in actuality means that the reader is given the green light to believe that there is a relationship between what she says about sleeping in a cherrytree in bloom under a full moon and about imagining a life in marble halls, and cognitively acts accordingly. It does not take the reader much effort to locate and access a productive context: on accessing the entries of the concepts in question, he will come across pertinent information about cherry-trees in bloom, moonlight and marble. What is pertinent, and what the reader of the original text will most probably select in his contextual search, is the fact that the blossoms of cherry-trees are white, that moonbeams are silver and that white things - such as blossoms- acquire a special lustre under them; also, that there is a certain kind of polished marble, likely to be found in a palace, which also looks lustrous, pale and silvery. Having accessed this stored information, consisting perhaps in visual evocations of these elements rather than the verbalisations presented above, the reader will at once identify the relevance of Anne's utterance: the sight of a cherry-tree in full bloom in the moonlight reminds her of a marble palace in virtue of their shared chromatic characteristics.

This implicature is indispensable for finding a straightforward interpretation consistent with the principle of relevance: it is the only way in which Anne's utterances can yield sufficient contextual effects at tolerable effort cost. Moreover, the original reader is entitled to believe that the author, when putting those words in Anne's mouth, had very strong assumptions about which context was accessible to him, they being members of the same community, which is tantamount to saying that the author's responsibility is unquestionable and the reader's choice has been strongly constrained -it is an instance of strong communication.

It must be noted that this first and stronger layer of implicatures does not involve the identification of Anne's utterance as an intertextual reference: an interpretation consistent 
with the principle of relevance is available even if Anne is thought to be engaging in descriptive use of language.

(b) Nevertheless, the recovery of a second layer of implicatures does hinge on the identification of the interpretive dimension of the utterance: Anne's remark rings a bell and suggests the reader that he should continue processing against the background of an extended context -the title of the ballad "I Dreamt that I Dwelt in Marble Halls". The utterance is therefore spotted -and interpreted- as a representation of another representation.

This identification gives rise to several weaker implicatures. Most obviously, the reader will interpret the utterance as evidence that evoking the sight of a cherry-tree in full bloom in the moonlight has made Anne think of that particular ballad via the connection marble -which is direct evidence that she knows the song and that she has some sort of a poetic sensitivity allowing her to make such a mental association-, that she is quoting a verse from a light opera and that she is doing so in passing, almost covertly, making it part of her own speech.

The original reader would then compare all these traits with the stereotypical image of little girls which is available to him, perhaps even of little orphan girls, and interpret those evidences in the light of this context. The general conclusion drawn from this comparison -that Anne's speech, perhaps she herself, is atypical- are confirmed as a correct line of interpretation by immediately previous utterances: some lines before the station-master had suggested something about her (speech) being somehow unexpected (1997:50-51) and the narrator had been very explicit in communicating that Anne was "no commonplace soul" (1997: 51).

This range of implicatures, which add up to the impression which the reader has so far had of Anne, are weaker than the ones in the first layer, but still not very weak. It is true that they are not indispensable for the reader to find an interpretation consistent with the principle of relevance, since they rather function as a bonus and not as a sine qua non of its interpretation, but still the reader's responsibility is low in that he is provided with an obvious starting point for context extension and inference leading to an interpretation of high relevance to him.

(c) So far two layers have been identified: a set of very strong implicatures, indispensable for recognising the relevance of Anne's utterance, and a set of moderately weak implicatures, functioning as an additional relevant interpretation conveying an impression of the character. The second set of implicatures, as said above, is derived on the grounds of the identification of the utterance as an interpretively used representation, namely a representation of the title of the ballad "I Dreamt that I Dwelt in Marble Halls".

The original reader could at this point have felt satisfied and stopped processing, but it is not inconceivable that he proceeded to extend the context and decided to follow even further the line of interpretation triggered by the intertextual reference. Here the question of resemblance arises: the reader has recognised Anne's words as a representation of another representation which it resembles, but where does that resemblance end? Even if 
there is an obvious starting point for this line of inference, there is no definite point where the reader must stop recognising a resemblance between both representations.

Such an extension of context would go beyond drawing conclusions from the salient evidence that Anne is quoting the title of Balfe's ballad, and make the reader embark on exploring the stored information about the entire ballad -perhaps the text, or its gist-and about The Bohemian Girl itself, particularly its plot. Being contemporary to both Anne and the author, and belonging to the same cultural community, the original reader would not need to invest a lot of effort to access such information, and it is very likely that he would feel tempted to continue processing in view of the interesting contextual effects envisaged.

Most immediately, the reader would feel entitled to draw a parallelism between Anne and Arline, the gypsy girl. From it, a very rich set of possible assumptions can be generated. An interpretation of Anne's remark as evidence of her identification with the gypsy girl who dreams about living in marble halls is significant: she also dreams of a better life. The fact that she makes use of her imagination interpreted in combination with a context in which certain religious, moral and social values are strongly present yields interesting contextual effects. Moreover, the original reader would also know that at the end of the opera the gypsy girl discovers that she does not belong to the nomadic community with which she lives and finally returns to her noble origins. The reader could extend the similarity and interpret the reference as a sign that Anne, the poor, neglected orphan girl, will eventually turn out to be a princess as well, literally of figuratively. Perhaps she will, like Arline, find a lost parent, again perhaps literally of perhaps figuratively.

All implicatures constituting this set are weak: in the first place, none of them is indispensable for arriving at an interpretation consistent with the principle of relevance (while they were in the first layer); secondly, they are not even necessary for identifying the relevance of the utterance after having labelled it as an interpretively used representation, since the implicatures in the second layer will do. Therefore, the reader must accept a lot of responsibility for deriving them: it is in this way that this particular intertextual reference can be explained as an instance of poetic use. In Sperber and Wilson's (1995: 237) words: "the result is a quite complex picture, for which the hearer [here the reader] has to take a large part of the responsibility, but the discovery of which has been triggered by the writer".

\section{Making decisions I: interlingual descriptive vs. interpretive use}

What we have just presented is an analysis of an intertextual reference in relevance-theoretic terms. Such an analysis reveals itself as an aid to translators, who see how an understanding of the original text based on elusive and fuzzy notions such as hidden meaning, connotation, symbolism or covert intention is replaced by a more coherent view allowing them to make their decisions on safer ground. Nevertheless, it would be erroneous to think that the aid which RT can render the translator is limited to this, while in reality such analyses function as a mere first step in the way towards relevance-theoretic decision-making. A further step is taken by making Gutt's general reflections on translation specific. 
One of those reflections concerns the very nature of translation and therefore involves a fundamental choice on the part of the translator: that which determines whether she will engage in translation at all. Gutt (1991) rethinks the notion of translation as traditionally accepted and suggests that the boundary between translation proper and other instances of interlingual communication is marked by the distinction between interpretive and descriptive use. According to him, some communication situations in which two languages are involved do not qualify as translation since the role of the original text is incidental those instances of communication are explained as examples of descriptive use working across languages. In the context of the particular translation situation in question, in which a translator is given a copy of Maud Montgomery's Anne of Green Gables, engaging in interlingual descriptive use could for example take the form of writing an adaptation of the novel for the stage in a different language.

Some other communication situations do fall under the heading of translation proper: the role of the original text is crucial and the communicative act is explained in terms of interlingual interpretive use, where the notion of resemblance proves central. In the example discussed here, the translator would be wanting to translate the novel into a foreign language so that the members of a given community can have access to it.

Had the translator opted for the former alternative, that is, interlingual descriptive use, she would have seen her decisions constrained by the principle of relevance like in any instance of communication: she would have had to make conjectures about her interlocutors' cognitive environments and produce the ostensive stimuli which, to the best of her knowledge, would put them to the smallest possible effort and provide them with as many contextual effects as possible. But having opted for the latter alternative-interlingual interpretive use, translation proper according to Gutt-an additional constraint appears: that of resemblance to the original text. In other words: the translator must simultaneously pay attention to the source-language text (resemblance constraint) and the target-language readers (relevance constraint). A relevance-theoretic analysis of the former has been presented above. A relevance-theoretic analysis of the readers' sphere, which is equally necessary, as has already been discussed, follows.

\section{Advancing hypotheses about target-language readers}

In the translation situation discussed here, Anne of Green Gables is being translated a) into Galician, b) for a contemporary community and c) for a readership consisting mainly of children and young adults. The significance of this information in the light of RT hinges on the notion of cognitive environment as a source of the context that will be selected by the reader as a background for interpreting.

When the translator makes the indispensable conjectures about the readers' cognitive environments, she will surely arrive at the conclusion that her readership, young Galician readers, will not be capable of identifying the remark "You could imagine you were dwelling in marble halls" as an intertextual reference, for one thing: they lack the necessary 
information_their cognitive environments do not contain any assumption at all about the title of the ballad or about the existence of Balfe's operetta, let alone about its plot. As we have discussed somewhere else (Almazán Garcia, 1998) each feature in the situation makes such information even more unlikely to be part of the cognitive environments of the Galician readers: the cultural gap would be a hindrance even if the translation had been contemporary to the novel; it is made even more insurmountable, if possible, by the ninety years separating both readerships; moreover, the typical addressee's age makes, at least from a general point of view, almost risible the hope of finding readers with such a rare knowledge of passed, not particularly remembered elements of a foreign culture, and a linguistic competence allowing them to recognise one of those elements when it is presented to them in a translated form. While it is true that such an exceptional reader could indeed exist, the translator's conjectures must of necessity focus on the more general case.

The fact that the reader of the Galician version of Anne's remark does not have access to the context originally intended to function as a background for interpretation invites misunderstanding as a consequence of it becoming what Gutt (1991: 73) calls a "secondary communication situation". The difficulty of successfully responding to the relevance and resemblance constraints is therefore augmented.

Another reason why the identification and analysis of the potential readership of the translation reveals itself as crucial has to do with the very notion of relevance. The translator being a communicator, she must take the responsibility of producing a stimulus relevant to the readers, which means that she should not put them to unnecessary cognitive effort. What unnecessary effort exactly means depends in a way on the interlocutor, and the communicator should take pains in advancing valid hypotheses, given the central position of this assumption to the success of the translation, about the effort her readers are willing to invest.

The addressed reader belonging to an age group ranging approximately from eight to eighteen, the translator will find it prudent to assume that the cognitive effort which they are willing to invest in the reading of the Galician translation of Anne of Green Gables is at most moderate. Blakemore (1992: 37) puts it in intuitive terms: "Compare, for example, the effort you are prepared to put into processing utterances which are part of a conversation at a party with the effort you put into understanding a lecture". In the example in question, readers would be closer to the party than to the lecture situation: their aim when engaging in reading Montgomery's novel would probably be enjoying a light reading, and not in any way learning about the operatic scene in English-speaking countries a century ago or studying Maud Montgomery's use of intertextuality in this particular novel. Since the contextual effects which the readers are likely to be expecting are reasonable, they will be willing to invest only a reasonable amount of cognitive effort. The translator must be aware of this if she wants to succeed in what Gutt (1991: 180) calls "making intentions and expectations meet".

The target-language side of this communication -translation - situation is therefore characterised by being an instance of interlingual interpretive use (which implies an additional resemblance-oriented constraint), a secondary communication situation (the 
reader has no access to the context originally envisaged by the author) and involving a readership willing to make a cognitive investment moderate at most.

\section{Making decisions II: direct vs. indirect translation}

Having produced the hypotheses above, the translator must at this point embark on deciding for which translation strategy she will opt when translating Anne's remark "You could imagine you were dwelling in marble halls, couldn't you?", which in terms of Gutt's relevance-theoretic approach to translation is tantamount to selecting a point in the continuum ranging from direct to indirect translation.

In Gutt's (1991: 163) own words, "a receptor language utterance is a direct translation of a source language utterance if and only if it purports to interpretively resemble the original completely in the context envisaged for the original". Put loosely, this means that the translator would not attempt to bridge the gap between the originally envisaged context and the one to which Galician readers have access: her task would be limited to presenting the utterance in a foreign language, in this case Galician, and either relying on the reader's ability to supply the right context or simply washing her hands off the whole affair.

The translator would most probably feel that this option is out of the question, taken that, as said before, it is highly unlikely that the reader could ever supply the originally envisaged context, which would cause either a misinterpretation of Anne's remark (if readers arrive at an interpretation which is consistent with the principle of relevance but not the intended one) or even a total breach of communication (if readers cannot arrive at any interpretation consistent with the principle of relevance and feel that their cognitive efforts have been in vain).

The alternative is abandoning the claim of total resemblance to the original, that is, of direct translation, and generating an indirect translation: if the absence of the appropriate contextual implications makes it impossible for the reader to access the weak implicatures which convey a very rich impression of Anne, as has been discussed, then a way of surmounting such a gap is explicating those implicatures, with which the ultimate interpretation would be respected, if not accessed through the same succession of steps.

This option must be discarded as not feasible in practice: the very nature of the intertextual reference in question, which has been explained as an instance of poetic use, the open-endedness of the implicature-deriving process, the fact that it is the reader who must take most responsibility for extending the context or stopping the processing effort... make embarking on the generation of any sort of indirect translation a risky business indeed: to what extent is the translator entitled to supplant readers in deciding the point at which they want to -or have to- stop processing?

There is a further option to be considered: instead of an explication of implicatures, the necessary context could be provided in a footnote so that the situation could be as close to a spontaneous, primary communication situation as possible. But here again difficulty arises: such manoeuvre would considerably augment the cognitive effort to which readers 
are put, while yielding some contextual effects which, according to their expectations as presented above (enjoying a piece of light reading), are not very likely to be sought. Are those contextual effects worth such an increase in the effort demanded from the reader? Put in intuitive terms: does it pay?

The solution to the dilemma faced by the translator, who sees how apparently no point in the direct-indirect continuum suits the simultaneous combination of goals sought (relevance and resemblance), lies in the relevance-theoretic analysis of the intertextual reference which was presented above.

This particular case is fortunate in that, apart from the second and third layers of implicatures which were explained on the basis of interpretive and poetic use, there is a first layer which invites an interpretation consistent with the principle of relevance even when seen as an instance of descriptive use of language. In other words: Anne's remark can be relevantly interpreted even without spotting the intertextual reference. The Galician reader does have access to the immediate set of contextual assumptions about marble, full moons and cherry blossoms allowing him to interpret Anne's remark as ostensive evidence that she is making a comparison between the sight of a cherry-tree in bloom under the moonlight and a palace made of marble.

This makes direct translation plausible after all. The interpretation likely to be derived by target-language readers is present in the original text (first layer) and yields sufficient contextual effects at reasonable cost (no footnote). Moreover, it is consistent with Anne's tendency to intersperse everyday speech with poetic gems, developed all through the novel. At the same time, the translator does not need to make any potentially arbitrary cut in the open-endness of implicatures (no explication): the second and third layers remain intact for the exceptional reader who has access to the context originally envisaged to discover them.

In conclusion, the existence of a first layer of strong implicatures points to direct translation as the answer to the question about which position in the direct-indirect translation continuum should be chosen.

\section{Conclusions}

We have tried to show how RT can help the translator analyse the original text and make a translation decision. We do not claim that the decision is revolutionary, more fortunate or valid than any other, or that our time-consuming discussion is the only way to arrive at a solution which, it could be argued, is all too obvious. What we want to show is that, fortunate or unfortunate, obvious or not, this decision is well founded and justifiable, which means a step towards consistency and therefore towards higher-quality translations and reflections on translation. At any rate, it is an exercise of self-awareness which leads to selfconfidence in the practice of translation (Kussmaul, 1995: 32).

It is true that the chosen example is especially amenable to this sort of treatment owing to the fact that the first layer of interpretation does not depend on its intertextual nature. What the decision would had been had that providential layer been absent, as is often the 
case, must be explored before even stopping to consider the possibility of making valid generalisations about the utility of RT for the translation of intertextual references. In any case, we believe that the present discussion is a first step in that direction.

\section{Appendix I: "I Dreamt that I Dwelt in Marble Halls"}

I dreamt that I dwelt in marble halls

With vassals and serfs at my side

And of all who assembled within those walls

That I was the hope and the pride.

I had riches too great to count, could boast

Of a high ancestral name,

But I also dreamt, which pleased me most,

That you loved me still the same.

I dreamt that suitors sought my hand,

That knights upon bended knee,

And with vows no maiden heart could withstand,

They pledged their faith to me,

And I dreamt that one of that noble host

Came forth my hand to claim;

But I also dreamt, which charmed me most,

That you loved me still the same.

Source: Joyce (1992: 101), Brown in Joyce (1992: 234)

Appendix II: Possible translations into Galician according to the different strategies discussed

1. Indirect translation: explication of (some) implicatures

¿Va que sería doado imaxinar que moraba en salóns de mármore, como di esa canción na que unha cativa pobre soña que é princesa e que vive nun palacio? Moito me reinaría min, que eu tamén lle son pobre e orfa, coma a da canción. Mire que se ó final tamén descubro que non era un soño e que son de verdade filla dun conde...

[Back translation: "Wouldn't it be easy to imagine you were dwelling in marble halls, like in that song about a poor girl who dreams she's a princess and lives in a palace? Wouldn't I love that! Because I'm poor and an orphan too, you know, like the girl in the song. Just suppose I also find out that it wasn't a dream after all and that I'm actually the daughter of a count!"]

2. Indirect translation: footnote providing the missing context ¿Va que sería doado imaxinar que moraba en salóns de mármore?* 
* Referencia á canción "Soñei que moraba en salóns de mármore", pertencente a unha obra musical moi coñecida daquela. Arline, unha xitaniña que...

[Back translation: "Wouldn't it be easy to imagine you were dwelling in marble halls?* * Reference to "I Dreamt that I Dwelt in Marble Halls", a song from an operetta that was very popular at that time. Arline, a gypsy girl who..."

3. Direct translation

¿Va que sería doado imaxinar que moraba en salóns de mármore?

[Back translation: "Wouldn't it be easy to imagine you were dwelling in marble halls?"]

\section{Works cited}

Almazán García, Eva M. (1998): Traducción Comentada da Novela de Lucy Maud Montgomery Anne of Green Gables. Unpublished BA dissertation, Universidade de Vigo.

Barry, Wendy E., Margaret Anne DOODY and Mary E. DOODY JONES (eds)(1997): The Annotated Anne Of Green Gables by L.M. Montgomery. New York: Oxford University Press.

Beaugrande, Robert de and Wolfgang Dressler (1981): Introduction to Text Linguistics. London: Longman.

Blakemore, Diane (1992): Understanding Utterances. An Introduction to Pragmatics. Oxford: Blackwell.

Dahlgren Thorsell, Marta (1998): "Relevance and the Translation of Poetry". Revista Alicantina de Estudios Ingleses. 11: 23-32.

Gutt, Ernst-August (1991): Translation and Relevance. Cognition and Context. Oxford: Blackwell. Hebel, Udo (1991): "Towards a Descriptive Poetics of Allusion". In H.F. Heinrich, ed., Intertextuality. Berlin and New York: Walter de Gruyter, 135-164.

Joyce, James (1992): (annotated version with notes and introduction by Terence Brown) Dubliners. London: Penguin.

Kristeva, Julia (1986): "Word, Dialogue and Novel". In T. Moi Toril, ed., The Kristeva Reader. Oxford: Blackwell, 35-61.

Kussmaul, Paul (1995): Training the Translator. Amsterdam: John Benjamins.

Leppihalme, Ritva (1997): Culture Bumps. An Empirical Approach to the Translation of Allusions. Clevedon: Multilingual Matters.

Plett, Heinrich F. (1991): "Intertextualities". In H.F. Plett, ed., Intertextuality. Berlin: Walter de Gruyter, 3-29.

Sperber, Dan and Deirdre Wilson (1986/95): Relevance. Communication and Cognition. Oxford: Blackwell.

Tirkkonen-Condit, Sonja (1992): "A Theoretical Account of Translation -Without Translation Theory?", Target 4(2): 237-245. 